\title{
A DERRIDEAN APPROACH TO MUSICAL IDENTITY
}

\author{
LAUREL RALSTON \\ UNIVERSITY OF ALBERTA
}

The issue of musical identity — of what defines works of music, gives each its unique character and distinguishes them from one another-is one of the central issues in the philosophy of music. Too often in the philosophical literature it is approached as a purely theoretical question, one that can be answered adequately through careful intellectual consideration of scores and performances. The typical philosophical approach to the performance of Western art music, particularly that composed between the Baroque and Romantic eras, is to offer descriptions of how musical works come into being, what their origins may be, which of their structural and aesthetic elements must be observed and conserved in their representations, and so on. It takes the written notation of a musical work, the score, to be a kind of blueprint created by a composer, defining and describing an autonomous musical entity, the musical work, such that another person might perform it. The work is recognized paradoxically as something existing independently of, yet deriving its identity from, its origins with the composer.

In this essay I propose that an alternative to this approach can be constructed by analogy with the 'textual strategies' characteristic of Jacques Derrida's approach to literary theory, criticism and the philosophy of language. Philosophical accounts of literary identity have upheld the supposed immutability of the 'original version' of the text and allowed it to remain the 'ultimate reference' for its identity. Derrida, however, has pointed out the problematic nature of traditional thought regarding literary texts: that there is a certain tension between the recognition of the enigmatic nature of the identity conditions of a literary work and the continued belief that it is possible to articulate such conditions. The structure of writing, of all writing, 
precludes any notion of the written text as fixed and eternal, because signification, representation, and the substitution of one meaning or context for another all occur indefinitely within it and without closure. Writing works in such a way that it engages signified meaning "in its own economy so that it always signifies again and differs... [That] which is written is never identical to itself." 1 The centre that would enclose this economy, that could cause the chain of signification to close itself by linking the origin and the end and boiling all substitutions down to a single, cohesive interpretation, would transgress this structure of writing. Substitution as it occurs in writing does not simply happen once and for all; it is structurally bound to occur $a d$ infinitum. In music this encompasses the substitution of notation for sound-a dual structure set in motion by différance, the playing movement that emerges within musical practice not only as the theoretical interaction of possible interpretations, but also as the concrete exercise of creating sound, time and again: of playing music. This is the case with all written texts - they do not possess a simple origin, because they are originally iterable:

To say that marks or texts are originally iterable is to say that without a simple origin, and so without a pure originarity ${ }^{2}$, they divide and repeat themselves immediately. They thus become capable of being rooted out at the very place of their roots. Transplantable into a different context, they continue to have meaning and effectiveness.

Not that the text is thereby dehistoricized, but historicity is made of iterability. There is not history without iterability, and this iterability is also what lets the traces continue to function in the absence of the general context or some elements of the context. $^{3}$

In the case of musical works, too, it is philosophically dangerous to proceed as though such substitutions could be effected fully-as though a work's original identity were ever fully determined and capable of being restored—and to base one's ethics and sense of responsibility on the goal of minimizing the 'remainder', or that which defies substitution. However, rethinking traditional philosophies of music in

\footnotetext{
Derrida, 'Force and Signification,' p. 25.

2 Roughly, 'originarity' in Derrida appears to mean something like: autonomous and perdurable condition(s) that make possible the emergence of any given self-identical phenomenon as such.

3 Derrida, 'An Interview with Jacques Derrida,' in Acts of Literature, p. 64.
} 
order to accommodate this insight clearly does not require that concern for compositional intention and authenticity be abandoned-it simply sets in motion a process of critical thought that opens the field of musical interpretation beyond its traditional boundaries, making room for an ethics inclusive of practices and performances otherwise discouraged by traditional philosophies of music, and intensifying rather than obscuring the issue of musical identity. The musical work, if we speak of it, is, because of différance, perhaps an example par excellence of what Derrida calls a past that has never been present.

The work itself is endlessly deferred through signs-ideas, symbols on a page, words, and sounds. The eternal and immutable work is that elusive past that has never existed in and of itself but has always only been glimpsed through detours and deferrals, putting off indefinitely the moment of its appearance in full. The difference between the traditional approach and an approach issuing from a Derridean concept of writing is that while for the former the transparent representation of the work in performance is a practical impossibility, for the latter both transparent representation and the-work-in-itself are a structural impossibility.

These two types of impossibility, practical and structural, carry with them very different responsibilities. It appears that practical impossibilities still demand treatment as though they could be overcome. Everything that can be done to reveal the work as it is in itself must still be done, and done out of respect for and interest in the work and the composer. However, from a Derridean perspective, the transparent representation of the work is structurally impossible because the work will never be, has never been self-identical. Its identity is constituted by its constant differing from itself and others. So performers are not simply asked to find and demonstrate objective certainties about the work; they are called not only to account for what might be called the dominant reading — sanctioned by research and tradition-but also for the elements in the work that refuse to be assimilated to a dominant reading.

What can we say about a work that is never self-identical but which takes its identity from its difference from and division within itself? This description reflects the process of musical practice with uncanny accuracy, but what then is the appropriate response to a work that is not itself at the same time that it is itself? How does a performer do justice to a work whose identity is always differing and deferred? 
"What is a success when the possibility of failure continues to constitute its structure?"4

Clearly, failure to do justice is not only possible but inevitable, and Derrida's question challenges us to redefine success in terms that acknowledge this structural feature. This redefinition must amount to a shift in focus away from correct readings and instead toward responsible readings. According to Derrida, a responsible reading is one that takes account of the 'dominant' reading while at the same time deviating from it in a respectful and critical way. As with a literary text, a musical text (not just the written text in the traditional sense of the score, but also the written musical text insofar as the history of the work and its performances is always written) carries a dominant reading as one of its layers. Yet writing is conditioned by the possibility of other contexts, "for it must, by virtue of its iterability, perdure beyond the present moment of its inscription and even after the death of its author." ${ }^{, 5}$ When a composer writes, she too writes from within this condition, not from outside it. It is therefore impossible for her to control absolutely the chain of signifiers that she inscribes. Consequently, an ethics of performance should no longer be focused solely on determining and realizing compositional intention, for this is not the only origin of what is written. It must also account for what exceeds intention and context, whose meaning cannot be discovered by appeal to the original and lost context but must instead be created in the present, which is always another present of inscription. Derrida writes, "the category of intention will not disappear; it will have its place, but from this place it will no longer be able to govern the entire scene and the entire system of utterances." 6

The performer is thus called upon to make a "decision of justice... [that] begins, it ought to begin, by right or in principle, in the initiative that amounts to learning, reading, understanding, interpreting the rule, and even calculating." "The must first analyze the validity of the rules that may apply (rules of performance practice, traditions of interpretation), and then their applicability to the specific instance before them in the singularity that is each individual musical work, and in each ethical encounter with the work, which is to say the entire continuum of her practice. This

Derrida, 'Signature Event Context,' p. 324.

Ibid., p. 34.

Derrida, 'Signature Event Context,' p. 326.

7 Derrida, 'Force of Law,' in Acts of Religion, Gil Anidjar, ed., (New York: Routledge, 2002), p. 252. 
must be the first step because "if calculation is calculation, the decision to calculate is not of the order of the calculable, and it must not be so." "Justice," writes Derrida, "always addresses itself to singularity, to the singularity of the other, despite or even because it pretends to universality. Consequently, never to yield on this point, constantly to maintain a questioning of the origin, grounds and limits of our conceptual, theoretical or normative apparatus," this questioning of rules, is not a mark of disrespect for justice of law, but one of sensitivity to its power.

Where this questioning leads to differences in interpretation and performance, the result is a testament to the richness of the musical work, to its refusal to be exhausted, its differrance. J. Hillis Miller writes, in The Ethics of Reading, that "the value of a reading, against all reason, lies in its difference and deviation from the text it purports to read." 9 This statement radically opposes the Platonist viewpoint on musical performance, which seeks the maximum correspondence between performance (reading) and text (work), and judges performance based on the degree of correspondence rather than on the quality and justness of the deviation. The endless repetition of a single reading or the assertion that only a single correct reading exists that could fully constitute or fully reveal the true identity of the work (regardless of whether or not this has already taken place, which of course it has not) does not do justice to différance, to the work or to the performance. The alternative at hand here is that the meaning of the work, however 'meaning' is defined, hovers in the differences between performances; it can never be exhausted by a single performance. ${ }^{10}$ This condition is not generally disputed by musical Platonists, but the same criticism may be made of them that Derrida makes of J.L. Austin, that in spite of recognizing that the account at hand is exposed to failure-failure, that is, to maintain meaning across a heterogeneous field of communication-they do not ask themselves "what consequences derive from the fact that something possible-a possible risk-is always possible, is somehow a necessary possibility. And if, such a necessary possibility of failure being granted, it still constitutes an accident."11 Musical

\footnotetext{
8 Ibid., p. 252.

9 J. Hillis Miller, The Ethics of Reading, (New York: Columbia University Press, 1987), p. 118.

10 This statement applies to formalist accounts of musical meaning as well, for insofar as structural meaning too is revealed through performance, the manner of performance will cause certain structural elements to appear more prominently and others less so, and thus will affect, if not the fact of those structural relationships' existence, then the listener's perception and assessment of their relative architectural and musical importance.

11 Derrida, 'Signature Event Context,' p. 324.
} 
Platonism does not offer a satisfactory account of the myriad meanings that, in differing from one another, even contradicting one another, identify a musical work; whereas a Derridean approach incorporates this phenomenon as a success rather than a failure of the structure of music and musical interpretation.

In an interview, Derrida describes the conditions of reading thus: "What goes for 'literary production' also goes for 'the reading of literature.' The performativity we have just been talking about calls for the same responsibility on the part of the readers. A reader is not a consumer, a spectator, a visitor, not even a 'receiver.' So we find once more the same paradoxes and the same stratifications." ${ }^{\prime 12}$ Conceptualized in this way, reading is not a passive activity, one of simply taking in what another consciousness has offered, but an active process of both challenge and surrender to the text at hand. Responsible musical practice should also exemplify this process. The endless differing of performances among them selves and of performances from the works they represent is the fulfillment of this 'law' of différance. This is not to say that just any performance that deviates somehow from the work can be considered responsible. Miller writes: "If the response is not one of necessity, grounded in some 'must', if it is a freedom to do what one likes, for example to make a literary text mean what one likes, then it is not ethical...but an ethical act that is fully determined by political considerations or responsibilities...[or] is subordinated to the epistemological, to some act of cognition,"13 is also not ethical. In order for there to be justice, there must be freedom and choice, yet there must also be rules to challenge and limit that freedom. The performer must go through these detours in order to respond responsibly.

I would like to re-emphasize two points that emerged above: First, that deviation from the score is not just inevitable but desirable and illuminating, essential even to the musician's musical and personal growth-for all of this responsibility can be daunting - as well as to honouring and maintaining the work's vitality. Second, that clearly responsibility is not an issue that only becomes pressing by virtue of the potential public performance of any given interpretation. The call to responsible musical practice occurs at the first encounter between musician and work, lingers on throughout the process of going out from and returning to the work, and is then intensified when an audience gets involved. In many cases, the audience might be

12 'An Interview with Jacques Derrida,' in Acts of Literature, p. 51.

13 Miller, pp. 4-5. 
taken as a representative for the dominant interpretation of a work; they will come equipped with expectations and standards against which the performance will be judged. And while it might be granted that instances of deviation are perfectly acceptable in a practice room, when they occur in public they become much more controversial. Without wading into the debate over whether a performance constitutes a propositional-style assertion of how a work ought to be played, I will note that musicians are quite regularly expected to give performances that show the work in its best possible light, whether this is due out of respect for the composer (especially if he is dead), the work itself, or some other motivation.

Yet as we have seen, once traditional ideals have been abandoned, the question of the best possible light becomes almost unintelligible. By acknowledging the effects of différance on musical meaning and practice, we acknowledge not only the necessity of betraying the musical work through interpretation, but the responsibility to do so. Extensive ontological theories of music risk taking their object too seriously, and if there is one thing that I would assert of all happy musicians it is that they all maintain, for as long as they remain practicing musicians, a sense of fun in what they do. Being a musician is always, and always should be, becoming a musician-that is, the insistent, incessant challenge and re-definition of one's own technical and interpretative boundaries-just as meaning is always becoming itself in différance. Derrida's approach to meaning and to reading keeps in balance the two necessary acts of deviating from and returning to the work of music. Throughout musical practice, one must be willing to take detours, to appear to stray from one's prescribed route or to lose sight of one's destination, in order to reach the limits of interpretability. It is a failing of traditional philosophies of music that they do little to address the journey but concentrate on the destination instead.

I will venture here to give a concrete example from my own attempts at musical interpretation. Several years ago, in a lesson with an unfamiliar teacher, I played the second movement of a baroque trumpet concerto in my characteristically reserved fashion, and was soon interrupted with a question: What would this movement sound like if it were a funeral march? I tried to make my next rendition funereal; I was interrupted again: What would it sound like if it were a lullaby? Then: What would it sound like if it were a children's playground song?

What my teacher did in that lesson was ask me to stop playing the piece as I thought it should be played, maybe as I'd been told it should be played, and implicitly 
proposed that this kind of radical deviation from what was probably quite a neutral performance might lead to insight into the movement's character. Although the second movement of that concerto is not a funeral march, a lullaby, a playground song, or any of the other musical types that my teacher listed that day, the experience of trying to interpret them in those ways was an experience of challenging limits, of opening the music to new possibilities, and of finding unexpected sympathies between the sublime and the ridiculous versions of that movement. My teacher remarked that sometimes to find out how to make music beautiful you have to make it stupid first, and furthermore, that beautiful is almost always found on the threshold of stupid. This exercise was designed to help me push the music to its limits, to find its limits, but perhaps most importantly to become mindful of the limits I had imposed on it myself, intentionally or not, by challenging my own stylistic prejudices and habits. Looking back on it, the exercise evokes the double responsibility and Derridean notion of justice discussed earlier with respect to reading - to examine the rules and then to experiment with breaking them, find points of weakness or manipulability. Furthermore, it demanded that I take full responsibility for my interpretation. For the upshot of the ethics of reading and interpretation endorsed here is that in making deviation from the text or the work a responsibility, a duty, we have also made the reader and the musician more responsible. That is, once the pretence of letting the work speak for itself is abandoned, the appeal to a transcendent outside performance loses its force as well. In straying knowingly from the dominant interpretation we are called all the more urgently to account for our choices. 


\section{REFERENCES}

DERrIDA, J. (1987) 'Force and Signification', in Writing and Difference (Chicago: University of Chicago Press): pp. 3-30.

-- (1982) 'Signature, Event, Context', in Margins of Philosophy (Chicago: University of Chicago Press): pp. 307-330.

-- (1992) 'An Interview with Jacques Derrida', in D. Attridge (ed.) Acts of Literature (New York: Routledge): pp. 33-75.

-- (2002) 'Force of Law: The 'Mystical Foundation of Authority', in G. Anidjar (ed.) Acts of Religion (New York: Routledge): pp. 228-298.

Miller, J. H. (1987) The Ethics of Reading. (New York: Columbia University Press). 